\title{
INFLUENCE OF EVAPORATION-DEPOSITION GEOMETRY ON CONDUCTIVE THIN FILMS
}

\author{
J. GRIESSING \\ Siemens $A G$, München, FRG
}

(Received May 19, 1980)

\begin{abstract}
There is a striking dependence of the evaporation deposition geometry (i.e. angular distribution of the incident vapor beam) on the properties of deposited conductive films. This paper discusses solderability, adhesion and long-term stability of adhesion of Ti-Pd- $\mathrm{Au}, \mathrm{Ti}-\mathrm{Au}$ and $\mathrm{Ti}-\mathrm{Cu}$ films. In all cases the above properties were improved by an evaporation deposition geometry with steep angles of the incident vapor beam.
\end{abstract}

\section{INTRODUCTION}

It is a common experience of all practitioners of evaporation deposition technology that films deposited in two different deposition systems will sometimes exhibit very different properties. Thus it would seem not to be possible for a deposition technique chosen for one system to be used with the same results in another. The same is true even if measurable external parameters such as the type of source, the deposition and substrate materials, the starting pressure, deposition rate, soak time, glow-discharge and precleaning time, glow-discharge gas composition, residual gas composition, substrate temperature, etc., are absolutely identical. It is often overlooked that the difference between the arrangement of source and substrate in the two systems causes the substrate to experience the deposition process differently, More precisely, the angular range over which the source is "seen" by the substrate during film deposition will differ from one system to another. Although properties such as the reflectance of aluminum films ${ }^{1}$, leaching ${ }^{2}$ and the solderability ${ }^{3}$ of Ti-Pd-Au films have long been known to be influenced by the deposition angle, calculations of deposition geometries $9,10,7,5$ have in the past served almost exclusively for evaluating the thickness uniformity of films. Only step coverage and the metallization of through holes, which are likewise influenced by the deposition angle, have been investigated in detail. ${ }^{4,11}$ The very simple method of using coordinate transformations to calculate the angular distribution of the incident vapor beam at a substrate point during one complete deposition run has already been described elsewhere. ${ }^{11,5}$

Figure la shows, as an example, a cross section through this angular distribution. The distribution pattern is in this case a skew cone. The substrate point is hit from the direction of the $x$-axis at a shallow angle and from the direction of the negative $x$-axis at a steep angle. Figure $1 \mathrm{~b}$ provides a clear represen-

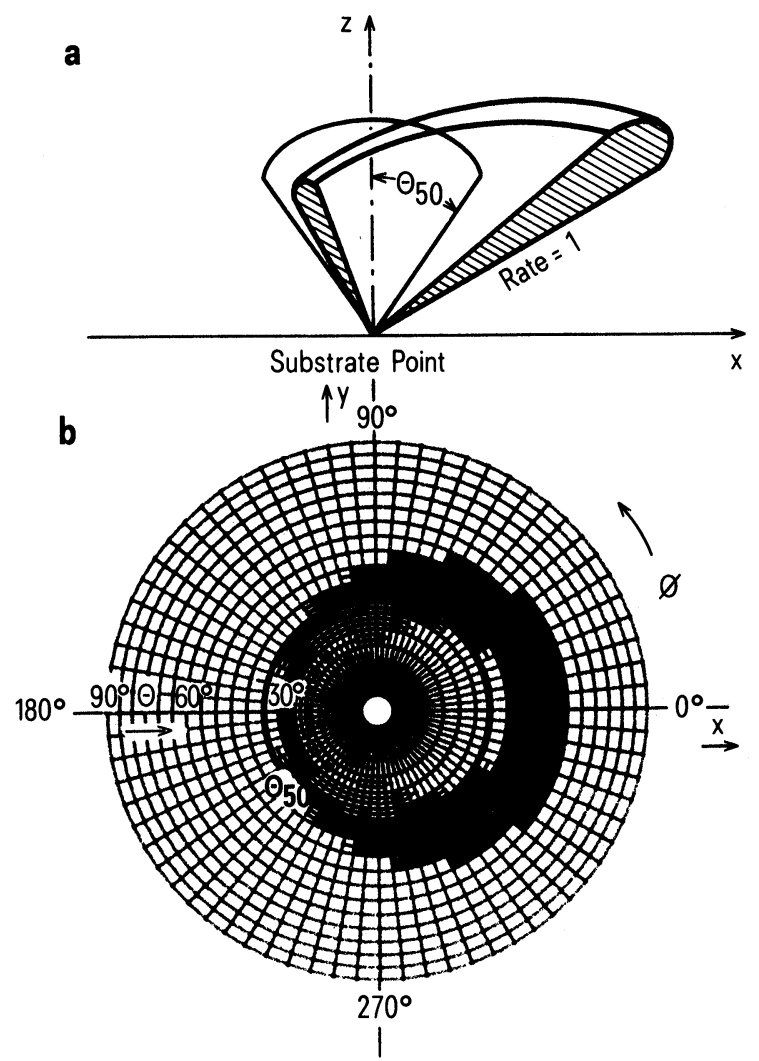

FIGURE 1 (a) Cross section through angular distribution of the deposition rate at a substrate point. (b) Azimuthal projection of the same angular distribution. 
tation of these conditions in the form of an azimuthal projection. To relate the three-dimensional "angular distribution" parameter to the measurable film properties, the cone aperture angle $\Theta_{50}$ is introduced to define the angular distribution. This is the cone through which exactly $50 \%$ of the condensed material passes. Any such unidimensional definition of a three-dimensional parameter is intrinsically imperfect. The uncertainty of some relationships between film properties and the deposition angle $\Theta_{50}$ may be attributable to this drawback.

The present investigation is concerned with the solderability, adhesion and long-term stability of the adhesion of Ti-Au, Ti-Pd-Au and Ti-Cu films. The Ti-Cu films were subsequently reinforced by electroplating of a $\mathrm{Cu}(6 \mu \mathrm{m})-\mathrm{Au}(2 \mu \mathrm{m})$ film. Both ceramic (MRC Superstrates) and glass (Corning 7059) substrates were used. In the case of the Ti-Au and Ti-Pd-Au films a $\mathrm{NiCr}$ film with a sheet resistance of $100 \Omega / \square$ was deposited on the substrate prior to the deposition of the conductive film. The dependence of the above film properties on the deposition angle as well as on the thickness of the deposited conductive film was investigated.

\section{EXPERIMENTAL}

An electron-beam gun was used as a source and a planetary fixture whose planetary axis $\Theta_{A}$ can be set to a desired angle was used as a substrate holder (Figure 2). The deposition geometry was moreover variable through an arbitrary choice of source location $x_{s}$. The mean deposition angle $\Theta_{50}$ was set by varying the setting angle $\Theta_{A}$ of the planetary rotator, while the width of the lateral area of the deposition cone was set by varying the source location $x_{s}$. Figure 3 shows, as an example, the angular distribution of the deposition rate for a steep deposition angle with a deposition cone having a narrow lateral area $\left(\Theta_{A}=0^{\circ}\right.$, $\left.x_{s}=30 \mathrm{~mm}\right)$ and a shallow deposition angle with a cone having a broad lateral area $\left(\Theta_{A}=-35^{\circ}\right.$, $x_{s}=143 \mathrm{~mm}$ ).

The test structures were defined by conventional wet chemical photolithograpy. Each test pattern consisted of forty $1 \times 1 \mathrm{~mm}^{2}$ or $2 \times 2 \mathrm{~mm}^{2}$ squares on a $2^{\prime \prime} \times 2^{\prime \prime}$ substrate. After stabilization by annealing in air $\left(0.5 \mathrm{~h}, 350^{\circ} \mathrm{C}\right)$ the structure were tinned by dip soldering in $\mathrm{SnPb}(60 / 40)$ solder. For measuring the adhesion, pins were first soldered to the $1 \mathrm{~mm}^{2}$

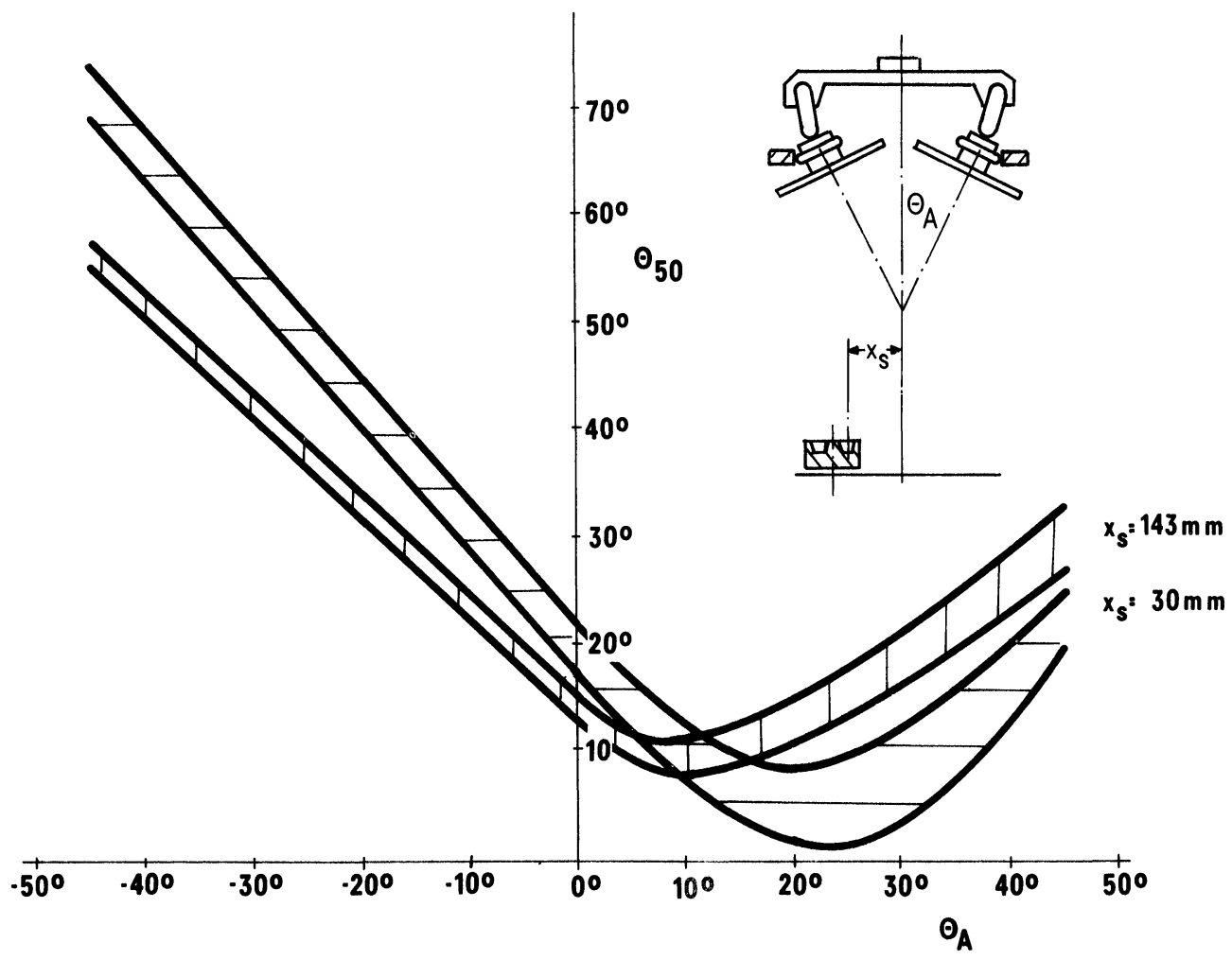

FIGURE 2 Deposition geometry. 

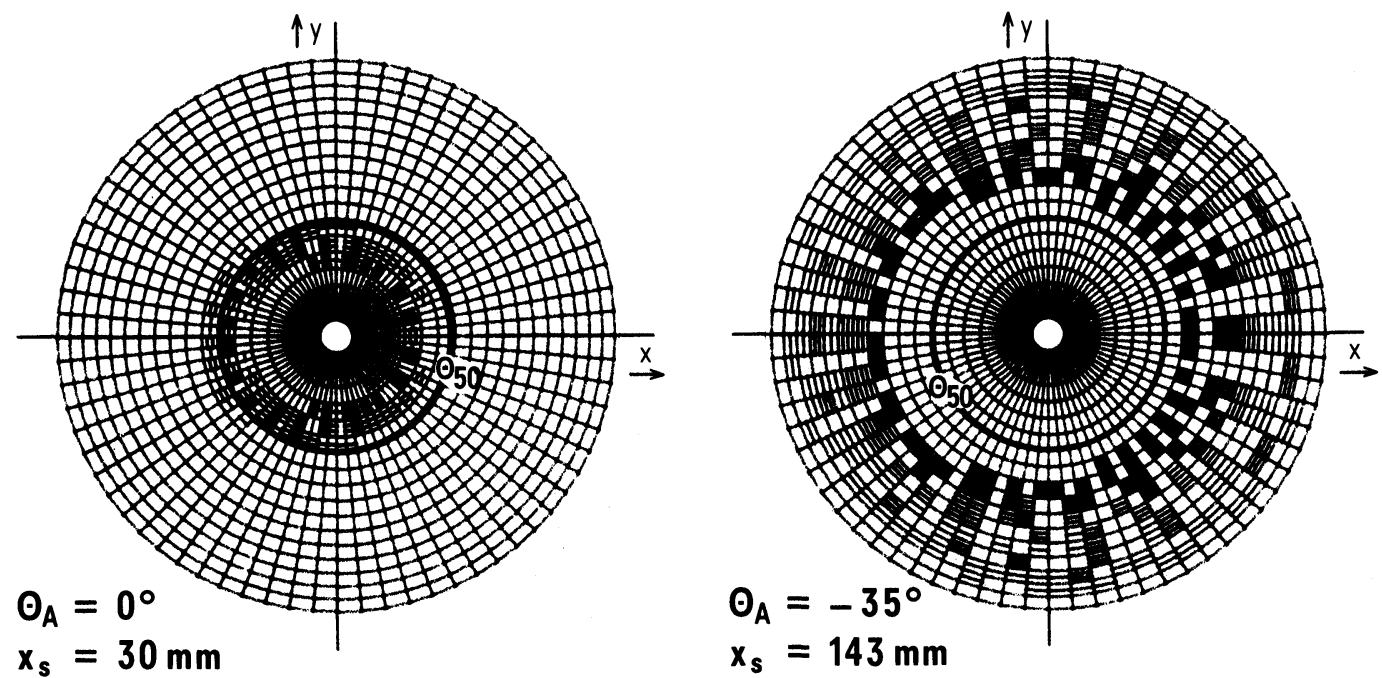

FIGURE 3 Angular distribution of the deposition rate for $\Theta_{A}=0^{\circ}, x_{S}=30$ (steep deposition angle) and $\Theta_{A}=-35^{\circ}, x_{S}=143 \mathrm{~mm}$ (shallow deposition angle).

squares and afterwards ripped out. ${ }^{8}$ The dissolution rate of the films was measured by holding each of the structured substrates for $5 \mathrm{~s}$ in the solder dip and afterwards counting the number of corners of squares into which the solder had receded. This procedure was repeated until all the corners were free of solder. The mean dissolution rate is calculated by dividing the film thickness by the randomized mean dissolution time. The long-term stability of adhesion was determined by storing the test patterns with attached pins at $150^{\circ} \mathrm{C}$ in air and ripping out further pins after $200 \mathrm{~h}, 500 \mathrm{~h}$ and $1000 \mathrm{~h}$.

\section{RESULTS}

The results are summarized on a qualitative basis in Table I.

\subsection{Dissolution Rate}

3.1.1 Ti-Pd-Au films. The thicknesses of the Ti-Pd-Au films were proportionally increased from $50 \mathrm{~nm}-400 \mathrm{~nm}-600 \mathrm{~nm}$ to $125 \mathrm{~nm}-1000 \mathrm{~nm}-$ $1500 \mathrm{~nm}$. The film thicknesses refer to measurements on films simultaneously deposited on glass substrates. Annealing causes the almost total diffusion of Pd into the Au film, resulting, except in the case of the $1500 \mathrm{~nm}$ thick $\mathrm{Au}$ film, in the surface turning gray. For investigating this sequence of films, $\mathrm{Al}_{2} \mathrm{O}_{3}$ ceramic with a roughness of $0.2 \mu \mathrm{m}$ on which an $\mathrm{NiCr}$ film had been deposited was chosen. The dissolution rate is shown in Figure 4 as a function of the deposition angle and the original Pd film thickness prior to annealing.

The bracketed figures represent the original Pd film

TABLE I

Influence of deposition geometry on film properties

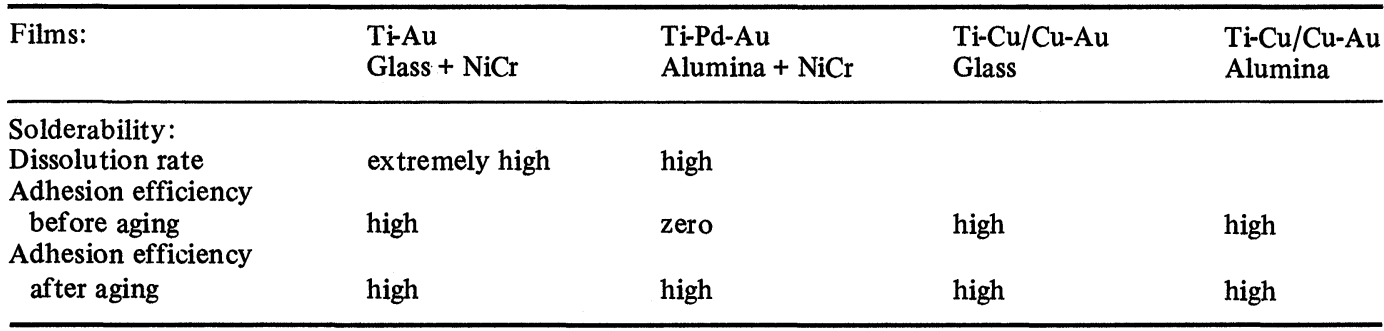




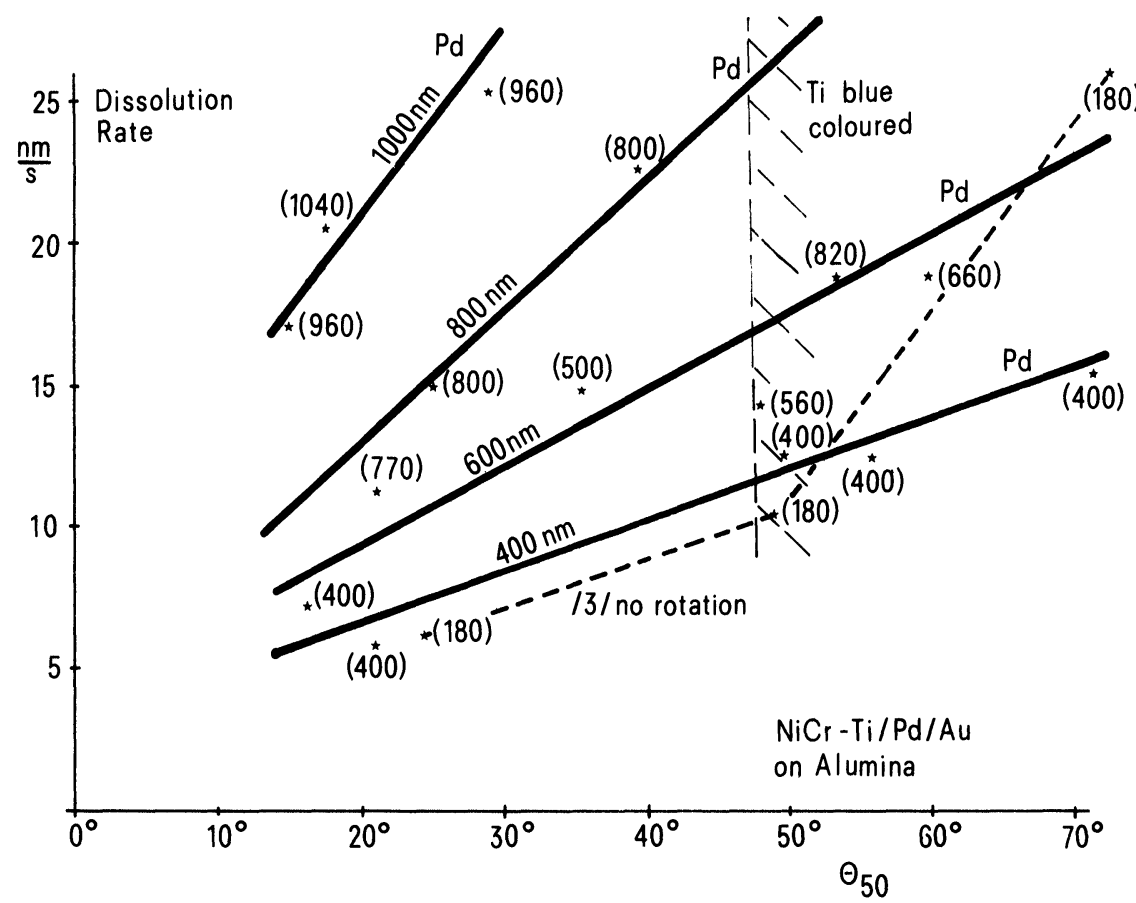

FIGURE 4 Dissolution rate of NiCr-Ti-Pd-Au films on alumina as a function of the deposition angle and the original Pd film thickness.

thicknesses. Each of the indicated measurement points represents a mean value based on either 484 or 648 single measurements.

The dissolution rate increases with both the deposition angle and the film thickness in the case of all films. From the economic aspect, this is a very important result which means that, as of an optimum film thickness, the solderability of Ti-Pd-Au films cannot be improved by increasing the film thickness, but only through an optimum choice of deposition geometry. The investigations disclosed an interesting side effect: at an angle of $\Theta_{50} \approx 47^{\circ}$ the Ti films on detached Pd-Au films turned a deep blue. Since this coloration was never observed in cases where the Pd-Au films that had been annealed were removed by etching, it can be assumed that the Ti film is oxidized, possibly by the flux agent, during the soldering operation. The reason why this effect is so greatly influenced by the deposition angle has not as yet been convincingly explained. The mechanism of the outdiffusion of $\mathrm{H}_{2} \mathrm{O}$ from pores in the alumina discussed by $\mathrm{Lach}^{6}$ cannot be accepted as an explanation because the blue coloration is also observed with films deposited on 7059 glass. The dashed curve in the diagram represents the measurements reported by Rickabaugh. ${ }^{3}$ These measurements were performed on films deposited on unmoved substrates in which shadowing is very pronounced in the case of large deposition angles. Thus the curvature of the curve, but not its steep lower portion, may be attributable to shadowing.

The dependence of the dissolution rate on the deposition angle is shown more clearly by the test structure used for qualitative analysis in Figure 5 than by the quantitative measurements shown in Figure 4. Seen on the left is a film deposited at a steep angle $\left(\Theta_{50}=15^{\circ}\right)$ and on the right a film deposited at a shallow angle $\left(\Theta_{50}=69^{\circ}\right.$, blue coloration $)$. Both samples are "completely detached" due to the solder having receded into all the corners as described above. Nevertheless, in the case of the film deposited at a steep angle the solder still wets almost the entire dotted area, whereas in the case of the film deposited at a shallow angle the solder has in some places entirely disappeared.

3.1.2 Ti-Au films These films were deposited on an $\mathrm{Ni}-\mathrm{Cr}$ film on a glass substrate. The Ti film thicknesses were between $50 \mathrm{~nm}$ and $130 \mathrm{~nm}$, while the 

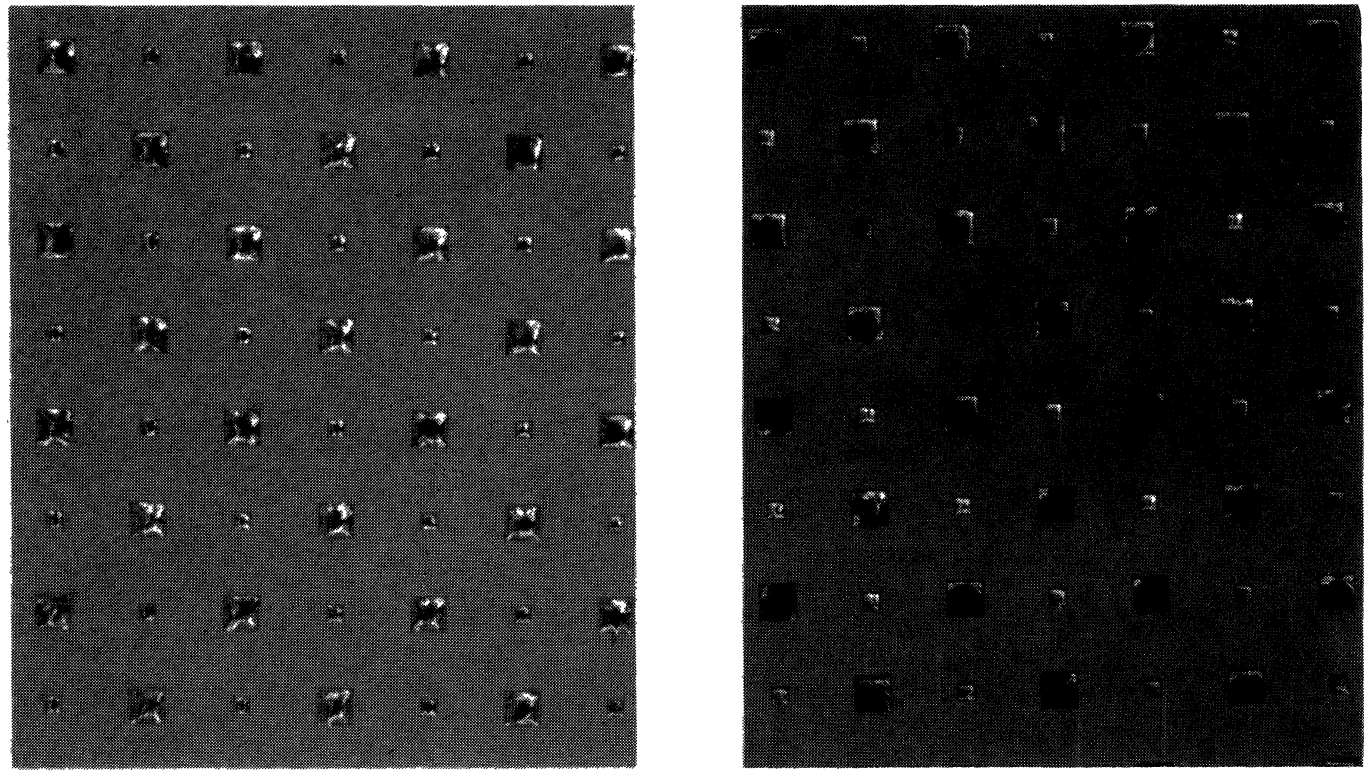

FIGURE 5 Test structure for measurement of dissolution rate (Ti-Pd-Au) after dip-soldering test. Left: Film deposited at steep angle, solder still wets almost the entire dotted area. Right: Film deposited at shallow angle, solder almost completely gone.

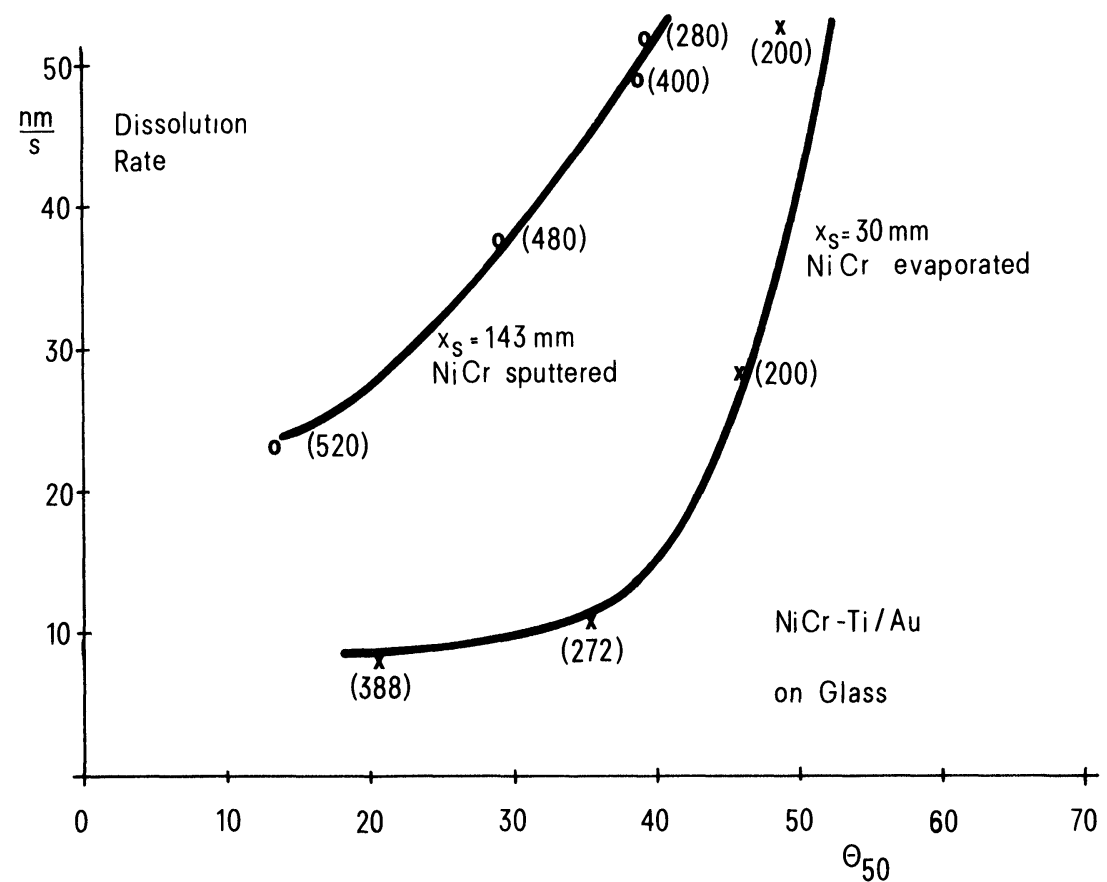

FIGURE 6 Dissolution rate of $\mathrm{Au}$ in PbSn solder on NiCr-Ti-Au films on glass substrate as a function of the deposition angle. 

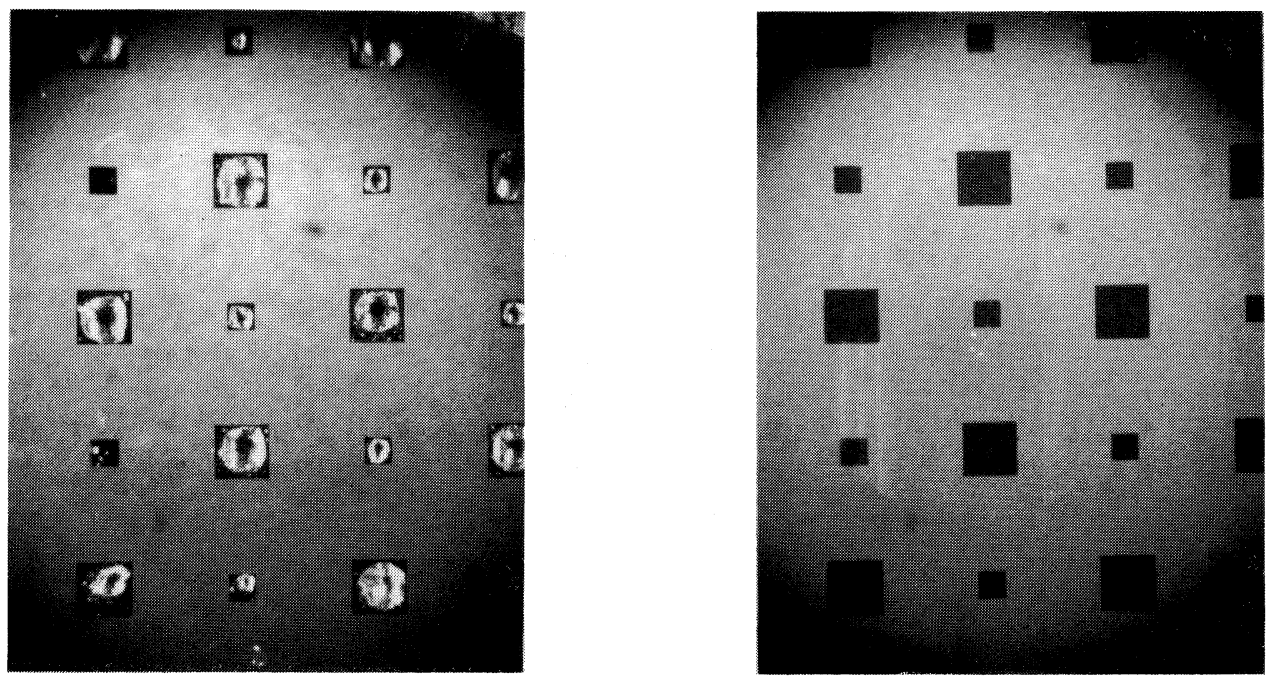

FIGURE 7 Test structure for measurement of dissolution rate (Ti-Au). Left: Film deposited at steep angle, pad wetted after $35 \mathrm{~s}$. Right: Film deposited at shallow angle, pad completely detached.

$\mathrm{Au}$ film thicknesses were between $200 \mathrm{~nm}$ and 520 $\mathrm{nm}$. Figure 6 shows the result. No dependence of the dissolution rate on the Au film thickness could be determined, but the influence of the NiCr film (sputtered or evaporation deposited) was observed. The dependence on the deposition angle is here more pronounced than in the case described above. Once again a comparison of the test pads following the dip soldering test (Figure 7) shows a marked difference between films deposited at a steep angle and those deposited with a shallow angle. The film on the left was deposited at an angle of $\Theta_{50}=14^{\circ}$ and dip-soldere $C_{i}$ seven times for 5 seconds, while the film on the right was deposited at an angle of $\Theta_{50}=42^{\circ}$ and already became completely detached after 3 seconds.

\subsection{Adhesion Efficiency}

3.2.1 Ti-Pd-Au films (Figure 8) As already reported by Griessing ${ }^{11}$ the adhesion of these films showed no

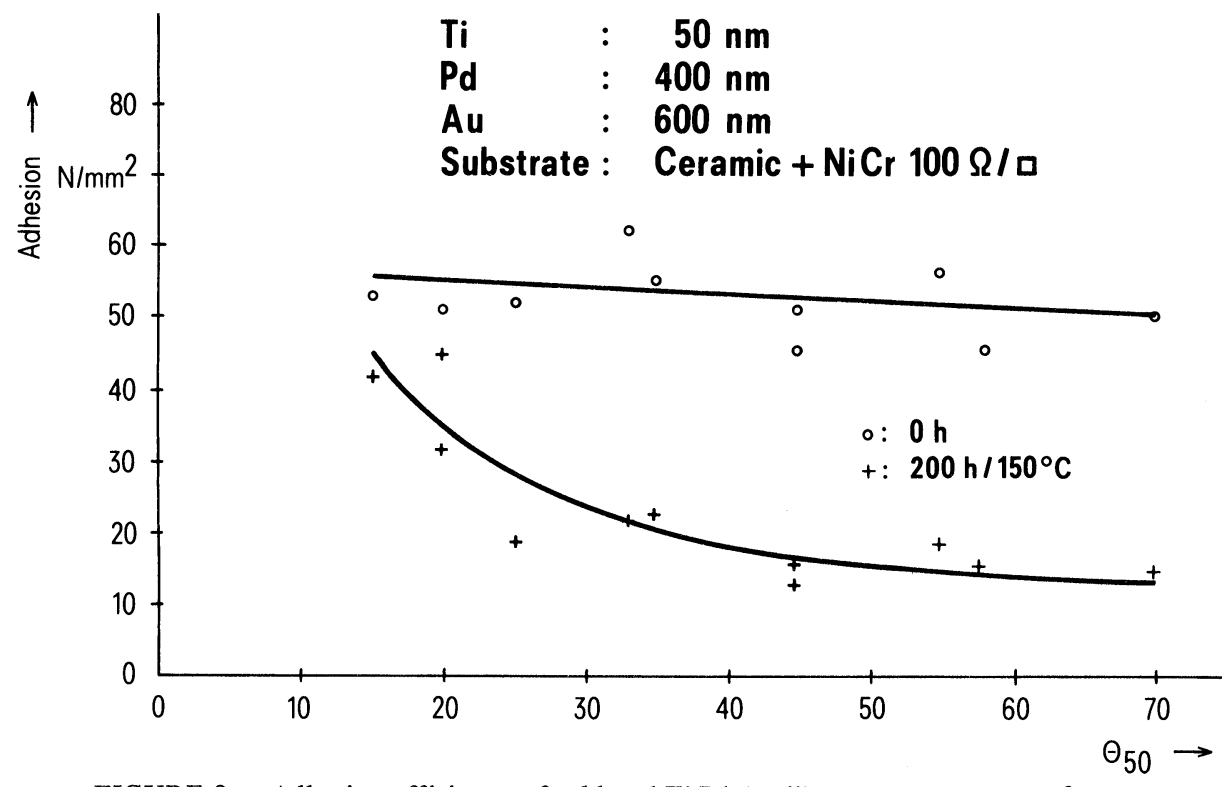

FIGURE 8 Adhesion efficiency of soldered Ti-Pd-Au films after aging at $150^{\circ} \mathrm{C}$. 

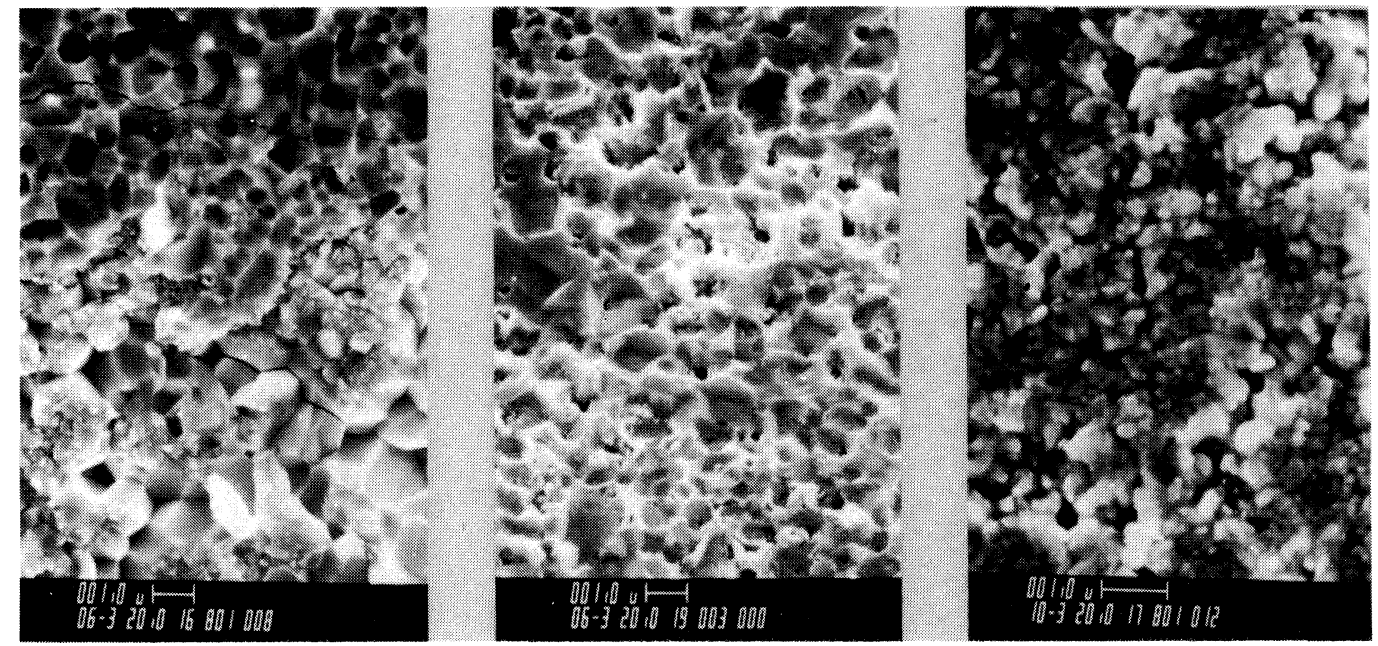

FIGURE 9 Scanning electron micrographs $(6000 \mathrm{x})$ of break after measurement of adhesion efficiency. a) Break in solder, $\Theta_{50}<20^{\circ}$; b) Break at Ti-Pd interface. Pd break faveoli still present, $\Theta_{50}>20^{\circ}$; c) Break at Ti-Pd interface. No break faveoli any longer visible, $\Theta_{50}>50^{\circ}$.

dependence on the deposition angle. This situation changed drastically after aging at $150^{\circ}$. After only $200 \mathrm{~h}$ the adhesion efficiency of films deposited at a shallow angle dropped to the intolerable level of $\leqslant 20 \mathrm{~N} / \mathrm{mm}^{2}$, whereas that of films deposited at a steep angle remained almost constant. It should be noted that a serious reduction in adhesion efficiency already begins at deposition angles of $\geqslant 20^{\circ}$ accom- panied by break point shifting from the solder to the Ti-Pd interface. Figure 9 shows scanning electron micrographs of three different breaks. Left: break in solder, strong adhesion. This result was obtained after the aging of films deposited at a steep angle. Middle: Ti-Pd interface. Residual Pd still visible in the form of breakage faveoli results in an adhesion efficiency of $20 \mathrm{~N} / \mathrm{mm}^{2}$ to $30 \mathrm{~N} / \mathrm{mm}^{2}$. Right: Ti-Pd interface. No

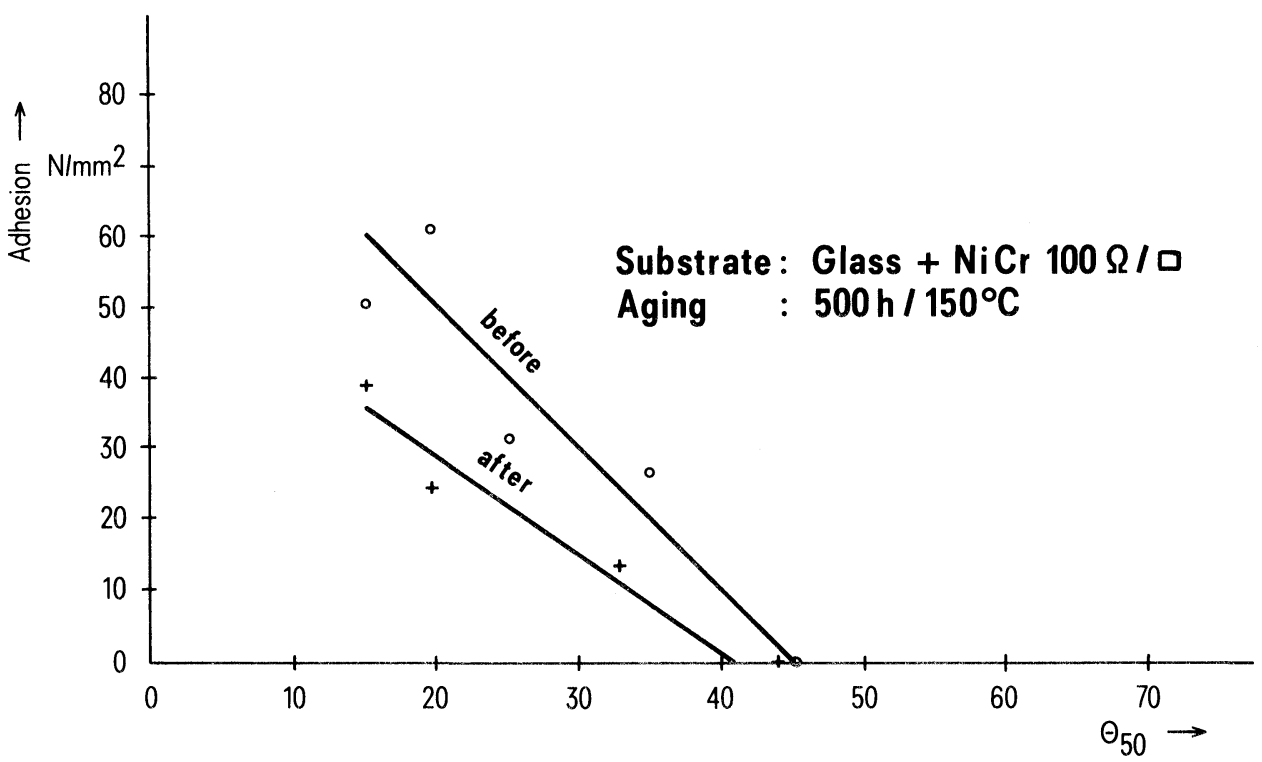

FIGURE 10 Adhesion efficiency of soldered Ti-Au films after aging at $150^{\circ} \mathrm{C}$. 


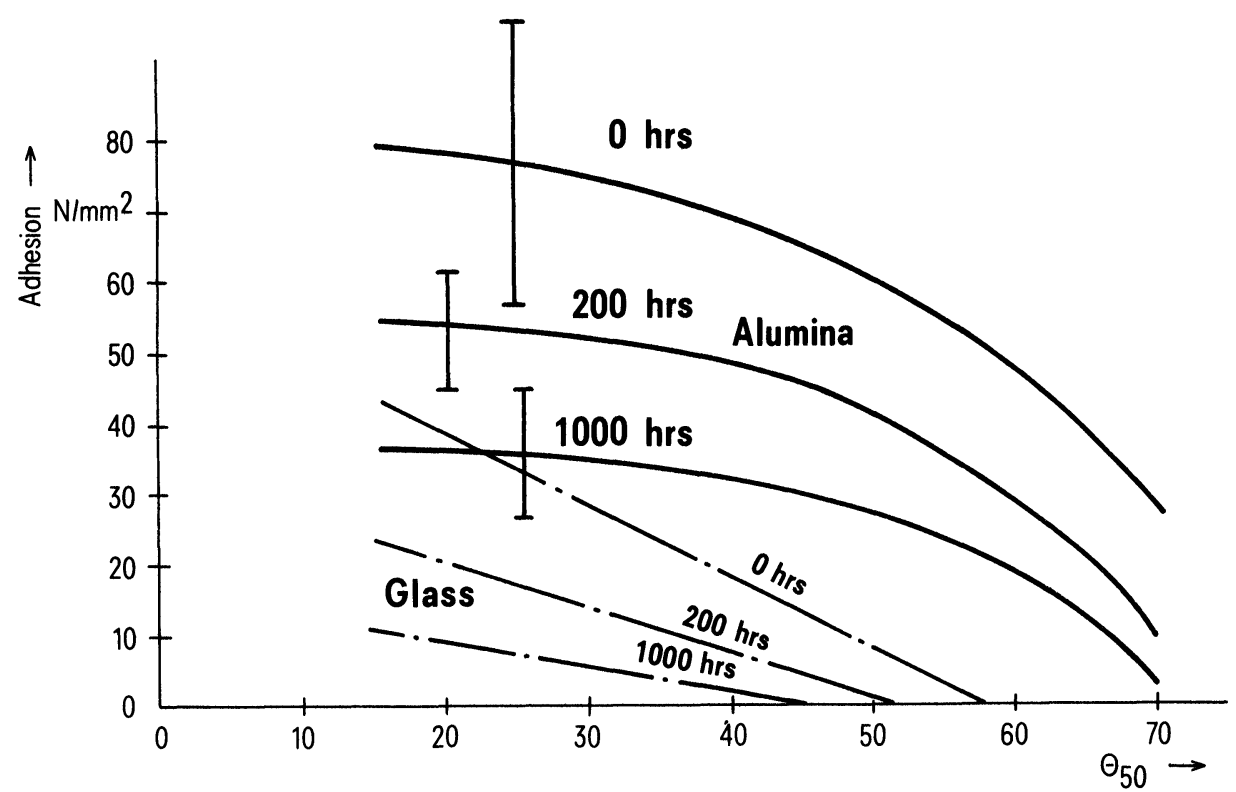

FIGURE 11 Adhesion efficiency of soldered $\mathrm{Ti}-\mathrm{Cu} / \mathrm{Cu}$ - $\mathrm{Au}$ films after aging at $150^{\circ} \mathrm{C}$.

residual $\mathrm{Pd}$ visible. This result is typical for deposition angles of $\Theta_{50}>50^{\circ}$. The adhesive efficiency is below $20 \mathrm{~N} / \mathrm{mm}^{2}$.

\subsubsection{Ti-Au-films (Figure 10) The adhesion} efficiency of these films already shows a pronounced dependence on the deposition angle directly after soldering with a further considerable increase after aging at $150^{\circ} \mathrm{C}$. For deposition angles of $\Theta_{50}>45^{\circ}$ the films already become detached within 3 seconds during the pretinning process.

\subsubsection{Ti-Cu/electroplated Cu-Au films (Figure 11)}

Electroplated $\mathrm{Cu}-\mathrm{Au}$ films evaporation-deposited on $\mathrm{Ti}-\mathrm{Cu}$ films on a glass or alumina substrate were not annealed after pattern definition. Their adhesion efficiency was found to be totally independent of both the Ti film thickness ( $25 \mathrm{~nm}$ to $135 \mathrm{~nm})$ and the $\mathrm{Cu}$ film thickness $(230 \mathrm{~nm}$ to $1390 \mathrm{~nm})$.

Alumina substrates Up to relatively high deposition angles $\Theta_{50} \approx 50^{\circ}$ high adhesion efficiency is obtained At still higher deposition angles the adhesion efficiency falls off sharply, approaching zero in the region of $75^{\circ}$. Here again the break point shifts with increasing deposition angle from the solder to the film. As of $\Theta_{50}>60^{\circ}$ the $\mathrm{Ti} / \mathrm{Cu}$ interface is the break point at all temperatures.

Glass substrates The adhesion efficiency of films deposited on a glass substrate is usually inferior to that of films deposited on alumina. The adhesion efficiency of films deposited at $\Theta_{50}>50^{\circ}$ is so poor that they can be pulled off with adhesive tape.

\section{CONCLUSION}

The tendency of Ti-Pd-Au and Ti-Au films to become leached during soldering is strikingly influenced by the deposition angle. The dissolution rate in solder increase: proportionally with the deposition angle for Pd-Au filn films and superlinearly for Au films. A drastic reductior in the adhesion efficiency is noted for $\mathrm{Ti}-\mathrm{Cu} /$ electroplated $\mathrm{Cu}-\mathrm{Au}$ films deposited on a glass or alumina substrate at an angle greater than $50^{\circ}$. The degradation of adhesion efficiency is in all cases due to the degenera tion of the Ti and conductive films. This observation would appear to explain the surprisingly small influence of the thickness of the conductive film on the solderability as well as on the long-term stability of adhesion. Both shadowing effects and crystal lattice mismatch between the Ti and conductive films may be responsible for poor adhesion.

\section{REFERENCES}

1. L. Holland, Vacuum Deposition of Thin Films, Londor 1963.

2. R. H. Minetti, L. Rickabaugh, Proc. El. Comp. Conf. IEEE (1977), 212. 
3. L. Rickabaugh, Electrocomp. Sci. Technol., 2 (1977), 43.

4. I. A. Blech, D. B. Fraser, S. E. Haszko, J. Vac. Sci. Technol. 15 1978, 13.

5. F. T. Goldstein Thin Solid Films 32 (1976), 43.

6. T. L. Lach, Proc. El. Comp. Conf. IEEE (1978), 5.

7. E. B. Graper, J. Vac. Sci. Technol., 10 (1973), 100.
8. H.-G. Kadereit and A. Schlemm, Siemens Forsch. $u$. Entwickl.-Ber. 6 (1977), 220.

9. B. S. Ramprasad and T. S. Radha. Thin Solid Films, 15 (1973), 55.

10. M. Krems and W. Schmidt, Vakuum Technik, 21. Jahrg., Heft 2/3 (1972), 33.

11. J. Griessing, Proc. European Hybrid Micro-Electron Conf., Ghent/Belgium, (1979), 229. 

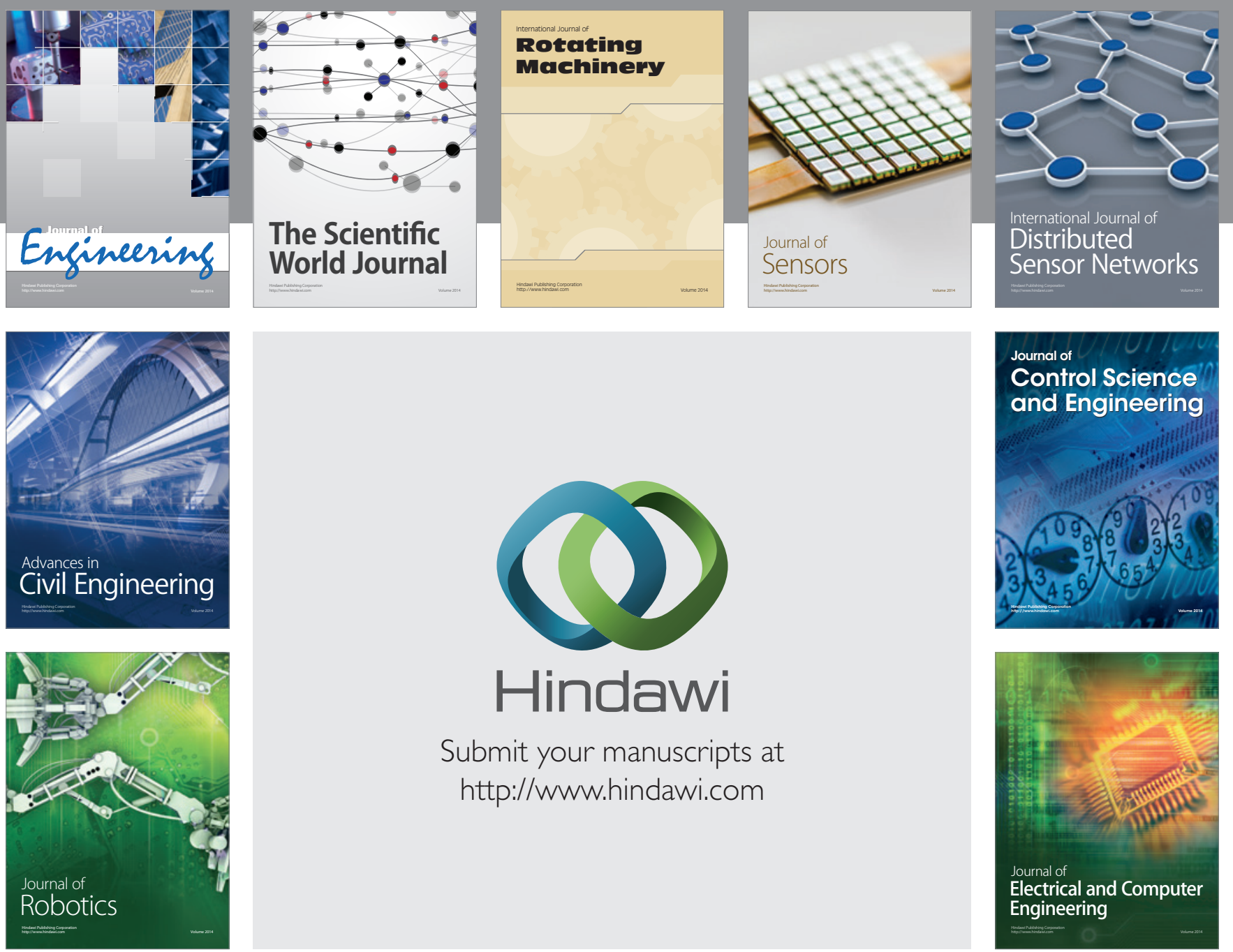

Submit your manuscripts at

http://www.hindawi.com
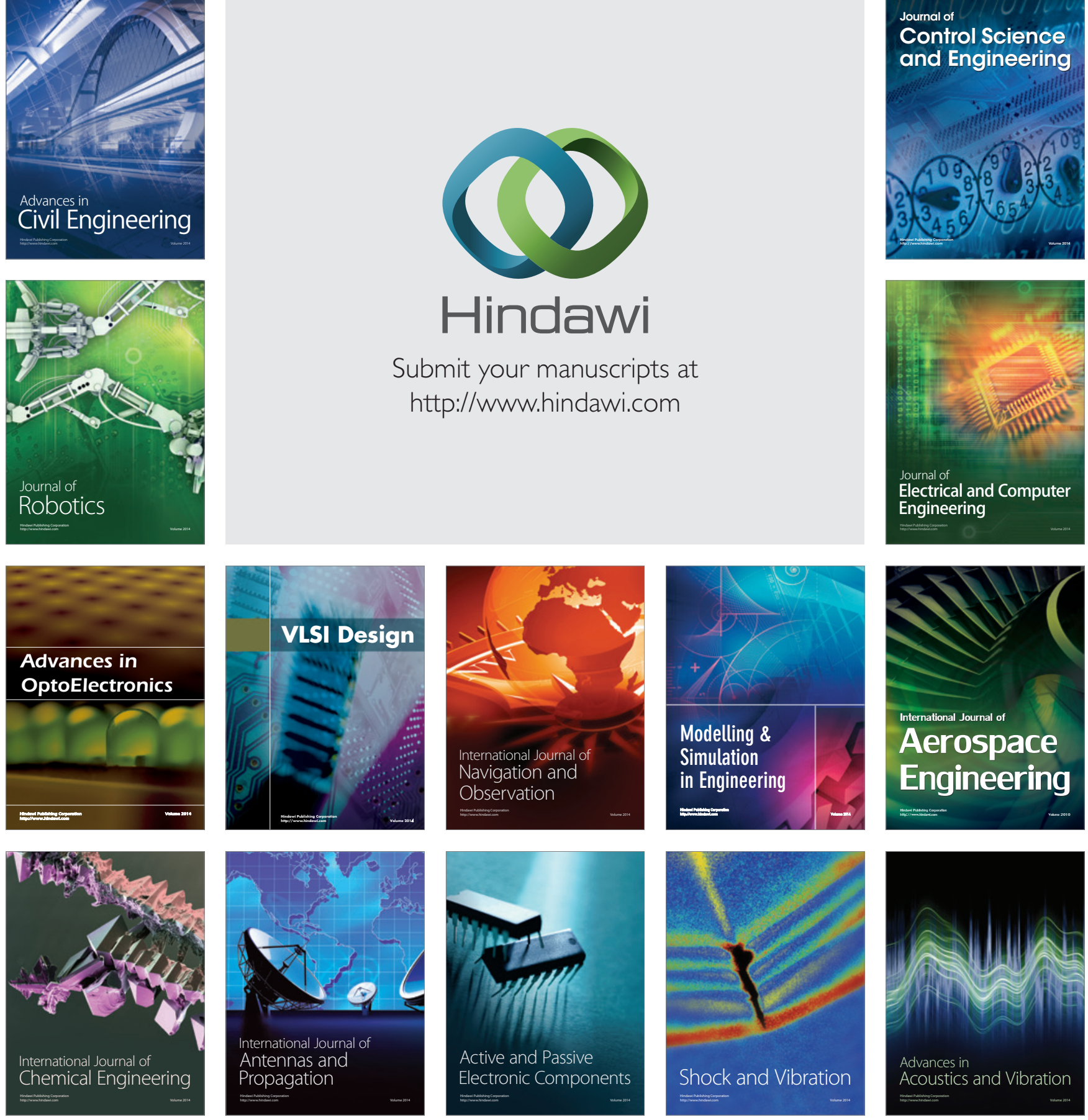